\title{
Grape and Apple Pomaces from Southern Brazil: Valorization of By-Products through Investigation of Their Antioxidant Potential
}

\author{
Mariéli Karling, Thariane C. Bicas, Vanderlei Aparecido de Lima and \\ Tatiane Luiza C. Oldoni*
}

\author{
Departamento de Química, Universidade Tecnológica Federal do Paraná(UTFPR), \\ 85503-390 Pato Branco-PR, Brazil
}

\begin{abstract}
The extraction process of bioactive compounds from grape and apple pomaces was optimized using a response surface methodology to evaluate the effect of ethanol concentration, time and temperature on the extraction of total phenolic content, antioxidant activity by radical scavenging 2,2-diphenyl-1-picrylhydrazyl hydrate (DPPH) method and individual phenolics by high performance liquid chromatography (HPLC). Optimizing suggests that the best condition for total phenolic and gallic acid extraction from grape pomace was obtained in intermediate level (60\% ethanol, $60{ }^{\circ} \mathrm{C}, 30 \mathrm{~min}$ ) while $80 \%$ ethanol, $75^{\circ} \mathrm{C}$ and $39 \mathrm{~min}$ was more efficient for $p$-coumaric acid extraction. For apple pomace the extract obtained with $50 \%$ ethanol at $75{ }^{\circ} \mathrm{C}$ and 39 minutes was more active by DPPH method and content of caffeic acid. Therefore, these abundant and inexpensive agro-industrial residues produced in Southern Brazil, are an important source of bioactive compounds that may be used as antioxidant substances in food and pharmaceutical industries.
\end{abstract}

Keywords: liquid-chromatography, extraction, phenolic compound, optimization, bioactive compound

\section{Introduction}

Phenolic compounds in food have received especial attention due to their beneficial effects to human health. ${ }^{1,2}$ Most of the biological properties of phenolics are related to their antioxidant activity. They are able to scavenge free radicals as reactive species of nitrogen and oxygen, naturally produced during aerobic metabolism. ${ }^{3,4}$ Studies have shown that daily consumption of antioxidants can protect the body against many diseases as cancers and cardiovascular diseases. ${ }^{2}$

Grapes, apples, their derivatives and by-products are considered source of antioxidant activity compounds because they have a high content of phenolic compounds as phenolic acids, several flavonoids, monomers (catechin, epicatechin and gallocatechin) and superior phenolic (proanthocyanidins or condensed tannins). ${ }^{3,5-8}$

When processing grapes and apples to produce wine, juice and jams, significant amount of waste is generated (peel, seeds, pulp and stems). It is estimated that only $20 \%$ of fruit weight is used and the remaining is discarded ${ }^{9,10}$

*e-mail: tatianeoldoni@utfpr.edu.br as animal feed and to make compost, destinations that do not generate economic gains for agribusiness and represent problems for disposal. ${ }^{11}$ Nevertheless, large amounts of the residual quantities of bioactive compounds are maintained into the vegetal tissues. Previous studies ${ }^{12}$ have shown that approximately $58 \%$ of phytochemical remain in the pomace during industrial processing.

Therefore, pomaces of grapes and apples become valuable sources by representing significant economic gains for producers, becoming raw materials for other activities and offer a new possibility of use by preventing or reducing the problems and environmental impacts related to the accumulation and disposal of these products..$^{13,14}$

There is a possibility of using these residues as natural antioxidant in the food and pharmaceutical industries ${ }^{15}$ and as an antimicrobial agent, prolonging the shelf life of products by inhibiting the lipid oxidation, ${ }^{16-18}$ enhancing color, flavor and aroma of foods. ${ }^{19}$ Shirahigue et al. ${ }^{20}$ showed a delayed lipid oxidation in processed chicken meat stored under refrigeration added with grape residue extracts (mixture of seed and peel) from Isabel and Niagara varieties.

Over the last ten years there has been a strong increase on studies focusing "pomace" and "antioxidants", which 
emphasizes the growing interest on these topics..$^{21-24}$ The chemical composition of grape and apple pomaces is varied and complex and it is intimately related to the geographical region and climate where it is produced. ${ }^{25}$ However, the available information on the polyphenolic and antioxidants from pomaces of Southern of Brazil, that has a wet temperature climate, with well-defined seasons is still limited and scarce, hindering the valorization of these by-products.

Extraction of bioactive compounds from plant materials is an important process and various techniques have been studied in this regard. ${ }^{26}$ The design of experiments (DOE) has been used in several studies of extractions for being considered a useful analytical tool, with application in the screening of the most relevant variables of a given analytical system. ${ }^{27}$ Therefore, it is important to apply DOE in studies covering many variables, as it makes possible the planning and carrying out in an organized way from a minimum number of experiments, saving time and financial resources and allows scientists to evaluate the influence of input and output variables aiming at increasing the process, improving the efficiency and quality of results..$^{28,29}$

Therefore, the aim of the present study was to optimize the extraction of phenolic compounds with antioxidant activity from grape and apple pomaces using central composite design (CCD).

\section{Experimental}

\section{Materials}

Standards including gallic acid, vanillic acid, caffeic acid, $p$-coumaric acid, ferulic acid, trans-resveratrol stilbene and reagents Folin-Ciocalteau, 6-hydroxy2,5,7,8-tetramethyl chroman-2-carboxylic acid (Trolox), 2,2'-azino-bis(3-ethyl benzothiazoline-6-sulphonic acid) (ABTS), 2,4,6-tripyridyl-s-triazine (TPTZ), 2,2-diphenyl1-picrylhydrazyl hydrate (DPPH), ethanol (EtOH) and methanol were purchased from Sigma Chemical Co. (St. Louis, MO).

\section{Preparation of materials}

The grape pomace samples (Vitis labrusca, Bordeaux variety) from the red wine processing were collected at a winery in Mariopolis city, Paraná state, Brazil and apple pomace samples (Malus domestica, Fuji variety) from juice processing were obtained in Treze Tílias city, Santa Catarina state, Brazil. Both collected in the year of 2014. The samples were lyophilized, grounded, weighed, packed and stored at $-6{ }^{\circ} \mathrm{C}$ until analysis.

\section{Experimental design and extraction procedures}

Response surface methodology (RSM) was used to optimize antioxidant activity and phenolic compounds extraction from apple and grape pomace. A central composite design with three independent variables was used: temperature $\left(35-85^{\circ} \mathrm{C} / \mathrm{X} 1\right)$, time $(21-45 \mathrm{~min} / \mathrm{X} 2)$ and ethanol concentration (40-90\%/X3). The three independent variables were coded at five levels $(-1.68,-1,0,1,+1.68)$, which resulted in an experimental design of 17 experimental points, including three central points.

Statistica software was used for designing experiments and statistical data analysis (ANOVA). Experimental data were analyzed to fit a second order polynomial regression containing linear and quadratic coefficient and two-factor interaction effects. Models and regression coefficients were considered significant when $p$-values were lower than 0.05 . The model equation of response $(\mathrm{Y})$ of three independent variables $(\mathrm{X} 1, \mathrm{X} 2$ and $\mathrm{X} 3)$ is:

$\mathrm{Y}=\beta_{0}+\sum_{\mathrm{i}=1}^{\mathrm{a}} \beta_{\mathrm{i}} \mathrm{Xi}+\sum_{\mathrm{i}=1}^{\mathrm{a}} \beta_{\mathrm{ii}} \mathrm{X}_{i}^{2}+\sum_{\mathrm{ij}=1(\mathrm{i} \neq \mathrm{j})}^{\mathrm{a}} \beta_{\mathrm{ij}} \mathrm{X}_{\mathrm{I}} \mathrm{X}_{\mathrm{j}}$

where $\mathrm{Y}$ is the dependent variable (total phenolic compounds-TPC, DPPH, caffeic acid, gallic acid, vanillic acid, $p$-coumaric acid, ferulic acid and trans-resveratrol stilbene), $\beta_{0}$ is the constant coefficient, $\beta_{\mathrm{i}}$ is the linear coefficient (main effect), $\beta_{\mathrm{ii}}$ is the quadratic coefficient and $\beta_{\mathrm{ij}}$ is the two-factor interaction coefficient.

A representative sample lyophilized of grape and apple pomaces $(2 \mathrm{~g})$ was extracted with a mixture of $25 \mathrm{~mL}$ of $\mathrm{X} 3$ ethanol:water mixture. The samples were homogenized using a vortex (Phoenix Luferco, model Ap56). After, the samples were heated at $\mathrm{X} 1{ }^{\circ} \mathrm{C}$ for $\mathrm{X} 2$ minutes and then cooled to room temperature and solvent was added if necessary to bring the final volume back to $25 \mathrm{~mL}$. Ethanolic extract of grape pomace (EEGP) and ethanolic extract of apple pomace (EEAP) were obtained. All extracts were filtered through a qualitative paper for total phenolic content (TPC) and DPPH analysis and then filtered using $0.45 \mu \mathrm{m}$ polytetrafluoroethylene (PTFE) syringe filter $\left(\right.$ Chromafil $\left.{ }^{\circledR}\right)$ for chromatographic analysis and stored at $-4{ }^{\circ} \mathrm{C}$ until analysis.

\section{Total phenolic content (TPC)}

The total phenolic content was determined by the colorimetric analysis using Folin-Ciocalteau reagent as described by Singleton et al. ${ }^{30}$ The reaction medium consisted of $0.5 \mathrm{~mL}$ of EEGP $\left(1.6 \mathrm{~g} \mathrm{~L}^{-1}\right)$ and EEAP $3.2 \mathrm{~g} \mathrm{~L}^{-1}$, $2.5 \mathrm{~mL}$ of Folin-Ciocalteau reagent diluted $10 \mathrm{~g} \mathrm{~L}^{-1}$ and, 
after five minutes, it was added $2.0 \mathrm{~mL}$ of sodium carbonate $\left(\mathrm{Na}_{2} \mathrm{CO}_{3}\right) 40 \mathrm{~g} \mathrm{~L}^{-1}$. The mixture was incubated at room temperature in the dark for 2 hours against ethanol as blank. Subsequently, the absorbance was measured using a spectrophotometer (model UV-Vis lambda 25, PerkinElmer) at $740 \mathrm{~nm}$. Gallic acid was used as reference at concentration ranging from 10 to $80 \mathrm{mg} \mathrm{L}^{-1}$ and the results of total phenolic content were expressed as $\mathrm{mg}$ gallic acid equivalents (GAE) $\mathrm{g}^{-1}$ of dry weight (DW).

Antioxidant activity using 2,2-diphenyl-1-picrylhydrazyl hydrate (DPPH) free radical scavenging method

DPPH free radical scavenging activity was measured according to the method described by Brand-Williams et al. ${ }^{31}$ The reaction medium consisted of $0.5 \mathrm{~mL}$ of $\operatorname{EEGP}\left(0.5 \mathrm{~g} \mathrm{~L}^{-1}\right)$ and EEAP $\left(1.6 \mathrm{~g} \mathrm{~L}^{-1}\right), 3 \mathrm{~mL}$ of ethanol and $0.3 \mathrm{~mL}$ of DPPH radical solution $0.5 \mathrm{mmol} \mathrm{L}^{-1}$ in ethanol. The mixture was incubated at room temperature in the dark for $45 \mathrm{~min}$ and the absorbance was measured using a spectrophotometer (model UV-Vis lambda 25, PerkinElmer) at $517 \mathrm{~nm}$. Ethanolics solutions of Trolox ( 15 to $100 \mu \mathrm{mol} \mathrm{L}^{-1}$ ) were used for calibration, and the results were expressed as $\mu \mathrm{mol}$ of Trolox g ${ }^{-1}$ of dry weight $\left(\mu \mathrm{mol}\right.$ Trolox $\left.\mathrm{g}^{-1}\right)$. The measurements were conducted in triplicate.

High-performance liquid chromatography with photodiode array detection (HPLC-PDA)

The high-performance liquid chromatography with photodiode array detection (HPLC-PDA) method was performed according to Oldoni et al..$^{28}$ using a liquid chromatography equipment (Varian 920-LC) coupled to an analytical column Varian C-18 RP $(250 \times 4.6 \mathrm{~mm}, 5 \mu \mathrm{m})$ and a detector of photodiode array (PDA). It was injected $10 \mu \mathrm{L}$ of EEGP and EEAP at a concentration of 5 and $6 \mathrm{~g} \mathrm{~L}^{-1}$, respectively. The mobile phase was composed of water:acetic acid $(99: 1, \mathrm{v} / \mathrm{v})($ solvent A) and methanol:acetic acid $(99: 1, \mathrm{v} / \mathrm{v})($ solvent $\mathrm{B})$ in gradient mode at a constant flow of $1 \mathrm{~mL} \mathrm{~min}{ }^{-1}$. The gradient started with $5 \%$ solvent
B to $7 \%$ of B in 7 minutes, $20 \%$ B in 15 minutes, $50 \%$ B in 30 minutes, $90 \%$ B in 50 minutes, and $95 \%$ B in 55 minutes. The column was maintained at a constant temperature of $30^{\circ} \mathrm{C}$. This work used authentic standards of vanillic acid, gallic acid, caffeic acid, $p$-coumaric acid, ferulic acid and trans-resveratrol stilbene. The identification was performed by comparison of absorption in ultraviolet at 280 and $320 \mathrm{~nm}$ wavelengths and retention times (Table 1).

\section{Results and Discussion}

Optimization by RSM was carried out to verify that the independent variables-temperature (X1), time (X2) and ethanol concentration (X3)-significantly influenced the process of extraction of phenolic compounds and antioxidant activity present in EEGP and EEAP. Influence was verified through the responses obtained in the analysis of total phenolic content (TPC), antioxidant activity by DPPH radical scavenger method and determination of phenolic compounds by HPLC for both extracts.

Based on the chromatographic analysis by HPLC, in EEGP it was identified and quantified gallic acid, caffeic acid, $p$-coumaric acid and trans-resveratrol and in EEAP caffeic acid (Figure 1). In both chromatograms some compounds were observed but not identified. Their ultraviolet (UV) spectra correspond to phenolic families analyzed as flavan-3-ol and dihydrochalcone $(280 \mathrm{~nm})$, hydrocinnamic acid $(320 \mathrm{~nm})$ and flavonol $(350 \mathrm{~nm}) .^{32}$

Farhadi et al. ${ }^{22}$ studied different cultivars, species and parts of grapes (seed, skin, peel and pulp) and identified other compounds with antioxidant capacities beyond those found in this work, particularly catechin, epicatechin, quercetin and rutin flavonoids. Tournour et al. ${ }^{8}$ conducted comparative studies of different varieties of Portuguese grapes using different methods of extraction, and their studies have revealed the presence of gallic acid, caffeic acid, syringic acid, catechin and epicatechin, and the major compounds were syringic acid and catechin.

Leyva-Corral et al..$^{5}$ evaluated apple pomace and a product formulated from that and identified phenolic acids

Table 1. Chromatographic parameters of phenolic compounds analyzed by HPLC

\begin{tabular}{lccccc}
\hline Phenolic compound & Retention time / min & Band UV / nm & Regression equation & $\mathrm{r}$ & ${\text { Linear range } /\left(\mu \mathrm{g} \mathrm{g}^{-1}\right)}^{\text {Gallic acid }}$ \\
Vanillic acid & 8.6 & 272 & $\mathrm{y}=0.3930 \mathrm{x}-0.5580$ & 0.999 & $0.5-30$ \\
Caffeic acid & 23.8 & $260-280$ & $\mathrm{y}=0.3378 \mathrm{x}-0.7586$ & 0.994 & $20-60$ \\
-Coumaric acid & 24.3 & 323 & $\mathrm{y}=1.005 \mathrm{x}-3.448$ & 0.998 & $3-15$ \\
Ferulic acid & 28.3 & 309 & $\mathrm{y}=1.6154 \mathrm{x}-0.6166$ & 0.999 & $1-20$ \\
trans-Resveratrol & 29.3 & 322 & $\mathrm{y}=1.512 \mathrm{x}-0.6894$ & 0.999 & $1-20$ \\
\hline
\end{tabular}




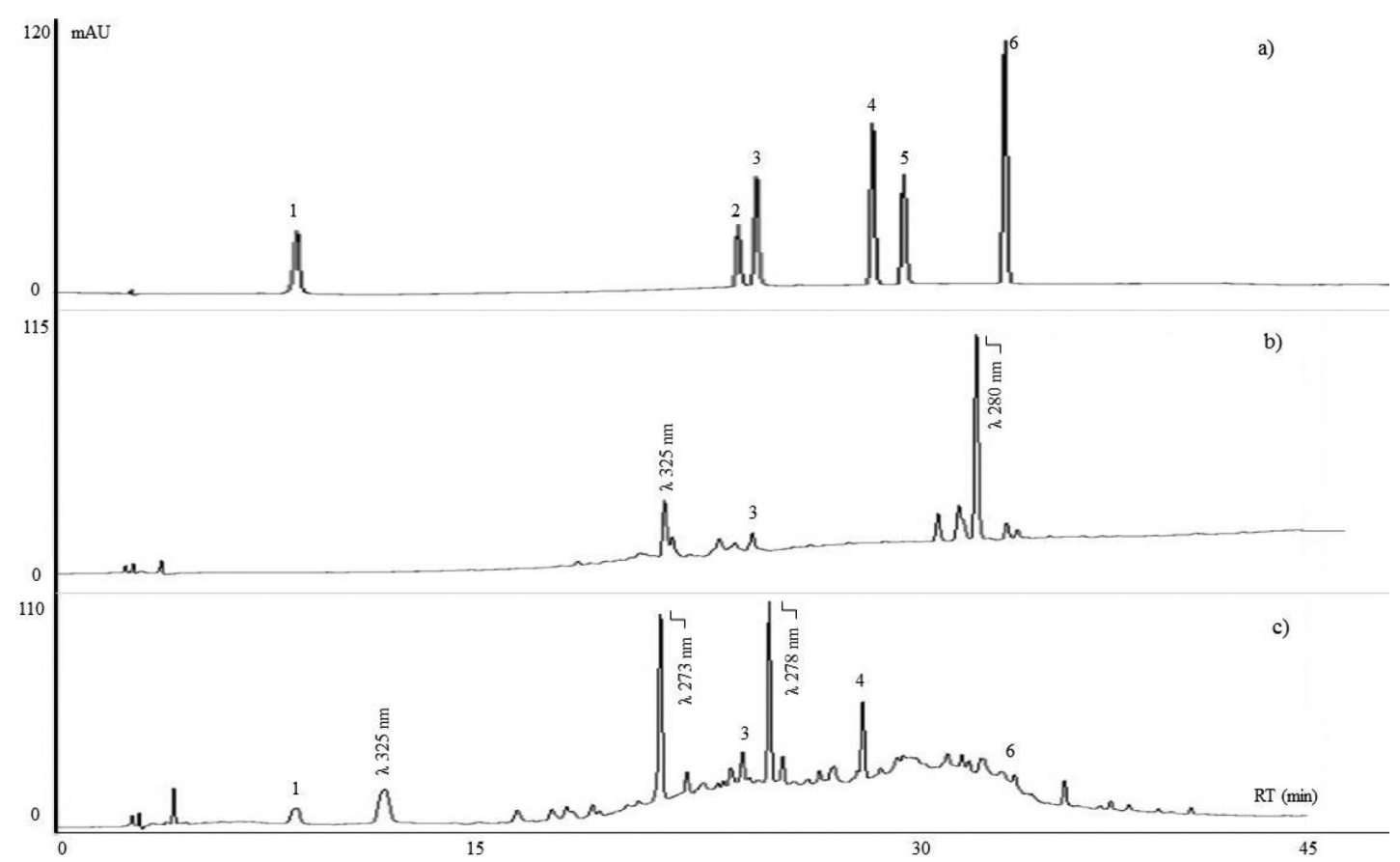

Figure 1. (a) High-performance liquid chromatography of standards used for identification and quantitation of phenolic compounds (wavelength of $280 \mathrm{~nm}$ ): 1. gallic acid; 2. vanillic acid; 3. caffeic acid; 4. p-coumaric acid; 5. ferulic acid and 6. trans-resveratrol; (b) EEAP chromatogram; (c) EEGP chromatogram.

and flavonoids in both, especially caffeic acid. Among the major phenols identified in apple pomace, García et al. ${ }^{33}$ described cinnamic acids.

After that, RSM was used to evaluate the influence of independent variables on dependent variables and regression coefficients. It was possible to demonstrate the terms of the model, quadratic and linear adjustments, as well as models of significant interactions between the terms. RSM analysis is performed by combining two independent factors related to dependent variable.

\section{Optimum extraction conditions for grape pomace}

For caffeic acid, trans-resveratrol and antioxidant activity by DPPH method no variable or interaction was statistically significant. The values of antioxidant activity and phenolic compounds for EEGP varied from 102.16 to $307.2 \mu \mathrm{mol}$ of Trolox $\mathrm{g}^{-1}$ and from 17.98 to $33.52 \mathrm{mg} \mathrm{GAE} \mathrm{g}^{-1}$ of dry grape pomace, respectively. The runs 10 and 11 , corresponding to the combination of intermediate levels of three input variables showed the highest responses for DPPH and TPC, respectively (Table 2).

The main effect, time of extraction had significant effect $(p<0.05)$ on the TPC (Table 3$)$. The content decreased by $49.7 \%$ when going from $30 \mathrm{~min}$, run R11 (33.52 $\mathrm{mg} \mathrm{GAE} \mathrm{g}^{-1}$ ) to 39 min of extraction, run R16

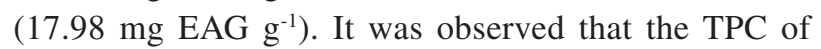
the extracts initially increased with increasing time until reaching a maximum, after which the TPC decreased with increasing time. It suggests that after the optimum extraction time occurred degradation of some thermolabile phenolic compounds, thus leading to a lower concentration of phenolic compounds.

The developed model can be considered statistically significant and predictive. F-value calculated was 7.05 times higher than F-tabulated with $95 \%$ of confidence (Table 3) for TPC. The models had satisfactory levels of adequacy $\left(\mathrm{R}^{2}\right)$.

The main effect, ethanol concentration was significant $(p<0.05)$ to extract gallic acid (Table 3$)$. The content increased 55.8\% when ethanol concentration going from $80 \%$, run R16 (5.70 $\left.\mu \mathrm{g} \mathrm{g}^{-1}\right)$ to $65 \%$, run R10 (12.90 $\left.\mu \mathrm{g} \mathrm{g}^{-1}\right)$. The maximum predicted TPC (33.52 $\mathrm{mg} \mathrm{GAE} \mathrm{g}^{-1}$ ) and gallic acid evaluated by HPLC $\left(12.90 \mu \mathrm{g} \mathrm{g}^{-1}\right)$ was obtained under the optimum extraction conditions of $65 \%$ of ethanol, $60{ }^{\circ} \mathrm{C}$ and $30 \mathrm{~min}$ for $\mathrm{EtOH}$ concentration, temperature and time, respectively (Table 2).

The extraction of phenolic $p$-coumaric acid (CUA) was influenced by interactions between time versus temperature and ethanol concentration versus temperature (Figure 2 and Table 3). At EtOH concentration of 50\%, the content of $p$-coumaric acid at 45 and $75^{\circ} \mathrm{C}$ was 21.2 and $19.4 \mu_{\mathrm{g} \mathrm{g}^{-1}}$, runs R2 and R15, respectively (Table 2 ). In comparison, the $p$-coumaric acid of the extract set 45 and $75{ }^{\circ} \mathrm{C}$ using $80 \%$ EtOH was approximately 18.1 and $34.2 \mu \mathrm{g} \mathrm{g}^{-1}$, runs R3 and $\mathrm{R} 13$, respectively. The samples extracted at 45 and $75{ }^{\circ} \mathrm{C}$ using $80 \%$ EtOH were significantly different. An increase 
Table 2. Central composite rotatory design and corresponding response values for ethanolic extract from grape pomace (EEGP)

\begin{tabular}{|c|c|c|c|c|c|c|c|c|c|}
\hline Run No. & $\mathrm{X} 1^{\mathrm{a}}$ & $\mathrm{X} 2^{\mathrm{b}}$ & $X 3^{c}$ & $\begin{array}{c}\text { Response DPPH } H^{\mathrm{d}} / \\
(\mu \mathrm{mol} \text { Trolox g-1 DW) }\end{array}$ & $\begin{array}{l}\text { Response TPC } / \\
\left(\mathrm{mg} \mathrm{GAE} \mathrm{g}{ }^{-1} \mathrm{DW}\right)\end{array}$ & $\begin{array}{l}\text { Response } \mathrm{CA}^{\mathrm{f}} / \\
\left(\mu \mathrm{g} \mathrm{g} \mathrm{g}^{-1} \mathrm{DW}\right)\end{array}$ & $\begin{array}{c}\text { Response } \\
\text { CUA }^{g} / \\
\left(\mu \mathrm{g} \mathrm{g}^{-1} \mathrm{DW}\right)\end{array}$ & $\begin{array}{c}\text { Response } \\
\mathrm{TR}^{\mathrm{h}} / \\
\left(\mu \mathrm{g} \mathrm{g}^{-1} \mathrm{DW}\right)\end{array}$ & $\begin{array}{c}\text { Response } \\
\mathrm{GA}^{\mathrm{i}} / \\
\left(\mu \mathrm{g} \mathrm{g}^{-1} \mathrm{DW}\right)\end{array}$ \\
\hline 1 & $35(-1.68)$ & $30(0)$ & $65(0)$ & 296.47 & 32.52 & 4.32 & 28.76 & 5.04 & 10.42 \\
\hline 2 & $45(-1)$ & $21(-1)$ & $50(-1)$ & 219.3 & 24.10 & 1.50 & 21.21 & 4.29 & 8.96 \\
\hline 3 & $45(-1)$ & $21(-1)$ & 80 (1) & 158.9 & 22.10 & 3.53 & 18.12 & 3.55 & 9.07 \\
\hline 4 & $45(-1)$ & $39(1)$ & $80(1)$ & 190.3 & 20.81 & 1.20 & 10.21 & 3.39 & 6.66 \\
\hline 5 & $45(-1)$ & 39 (1) & $50(-1)$ & 102.2 & 28.58 & 2.01 & 47.13 & 14.45 & 9.63 \\
\hline 6 & $60(0)$ & $15(-1.68)$ & $65(0)$ & 258.4 & 27.75 & 5.90 & 20.17 & 1.92 & 9.04 \\
\hline 7 & $60(0)$ & $30(0)$ & $40(-1.68)$ & 270.4 & 28.71 & 2.40 & 19.37 & 5.36 & 6.72 \\
\hline 8 & $60(0)$ & $30(0)$ & $90(+1.68)$ & 295.1 & 30.52 & 4.90 & 32.09 & 5.38 & 10.61 \\
\hline 9 & $60(0)$ & $30(0)$ & $65(0)$ & 281.8 & 33.52 & 2.60 & 34.22 & 14.00 & 12.56 \\
\hline 10 & $60(0)$ & $30(0)$ & $65(0)$ & 307.2 & 32.31 & 5.45 & 33.34 & 5.49 & 12.90 \\
\hline 11 & $60(0)$ & $30(0)$ & $65(0)$ & 202.3 & 35.73 & 2.46 & 23.60 & 6.37 & 11.79 \\
\hline 12 & $60(0)$ & $45(+1.68)$ & $65(0)$ & 261.1 & 27.38 & 2.38 & 27.39 & 7.89 & 10.26 \\
\hline 13 & $75(1)$ & $21(-1)$ & $80(1)$ & 261.1 & 27.58 & 2.51 & 34.22 & 5.81 & 12.56 \\
\hline 14 & $75(1)$ & $21(-1)$ & $50(-1)$ & 252.4 & 27.56 & 1.41 & 18.46 & 6.59 & 9.76 \\
\hline 15 & $75(1)$ & $39(1)$ & $50(-1)$ & 303.8 & 27.46 & 1.23 & 19.42 & 1.68 & 9.50 \\
\hline 16 & $75(1)$ & $39(1)$ & $80(1)$ & 136.9 & 17.98 & 1.25 & 17.66 & 5.14 & 5.70 \\
\hline 17 & $85(+1.68)$ & $30(0)$ & $65(0)$ & 218.3 & 26.02 & 4.70 & 32.78 & 12.43 & 11.58 \\
\hline
\end{tabular}

${ }^{\mathrm{a} X} 1$ : temperature $\left({ }^{\circ} \mathrm{C}\right)$; ${ }^{\mathrm{b} X} 2$ : time $(\mathrm{min})$; ${ }^{\mathrm{C}} \mathrm{X}$ : ethanol concentration $(\%)$; ${ }^{\mathrm{d} D P P H}$ : 2,2-diphenyl-1-picrylhydrazyl hydrate-antioxidant activity; ${ }^{\mathrm{e}} \mathrm{TPC}$ : total phenolic content; ${ }^{\mathrm{f}} \mathrm{CA}$ : level of caffeic acid; ${ }^{\mathrm{g}} \mathrm{CUA}$ : $p$-coumaric acid; ${ }^{\mathrm{h}} \mathrm{TR}$ : level of trans-resveratrol; ${ }^{\mathrm{i}} \mathrm{GA}$ : gallic acid; DW: dry weight.

Table 3. Analysis of variance (ANOVA), regression coefficients of the models, $\mathrm{R}^{2}$ values and F-value of the optimized second order polynomial models of antioxidant activity as measured by DPPH, phenol content (TPC), level of gallic acid, level of $p$-coumaric acid and caffeic acid level for ethanolic extracts of grape (EEGP) and apple pomace (EEAP)

\begin{tabular}{|c|c|c|c|c|c|}
\hline \multirow{3}{*}{ Term } & \multicolumn{3}{|c|}{ EEGP } & \multicolumn{2}{|l|}{ EEAP } \\
\hline & \multicolumn{5}{|c|}{ Coefficients of the models } \\
\hline & $\begin{array}{c}\text { TPC / } \\
\left(\mathrm{mg} \mathrm{GAE} \mathrm{g}^{-1} \mathrm{DW}\right)\end{array}$ & $\begin{array}{c}\mathrm{GA} / \\
\left(\mu \mathrm{g} \mathrm{g}^{-1} \mathrm{DW}\right)\end{array}$ & $\begin{array}{c}\text { CUA / } \\
\left(\mu \mathrm{g} \mathrm{g}^{-1} \mathrm{DW}\right)\end{array}$ & $\begin{array}{c}\text { DPPH / } \\
(\mu \mathrm{mol} \text { Trolox g-1 DW })\end{array}$ & $\begin{array}{c}\mathrm{CA} / \\
\left(\mu \mathrm{g} \mathrm{g}^{-1} \mathrm{DW}\right)\end{array}$ \\
\hline Intercept $\left(\beta_{0}\right)$ & 34.12 & 12.46 & 30.60 & 33.75 & 59.50 \\
\hline time $\left(\beta_{1}\right)$ & $-0.52^{\mathrm{a}}$ & $-0.50^{\mathrm{a}}$ & $1.07^{\mathrm{a}}$ & $1.34^{\mathrm{b}}$ & $0.01^{\mathrm{a}}$ \\
\hline EtOH concentration $\left(\beta_{2}\right)$ & $-1.19^{\mathrm{a}}$ & $0.19^{\mathrm{a}}$ & $-0.34^{\mathrm{a}}$ & $-3.74^{c}$ & $12.39^{\mathrm{b}}$ \\
\hline Temperature $\left(\beta_{3}\right)$ & $-0.43^{\mathrm{a}}$ & $0.38^{\mathrm{a}}$ & $-0.01^{\mathrm{a}}$ & $3.19^{\mathrm{c}}$ & $8.39^{\mathrm{d}}$ \\
\hline time $\times$ time $\left(\beta_{11}\right)$ & $-3.11^{\mathrm{d}}$ & $-1.12^{\mathrm{a}}$ & $-3.06^{\mathrm{a}}$ & $-1.11^{\mathrm{d}}$ & $-2.32^{\mathrm{a}}$ \\
\hline EtOH concentration $\times$ EtOH concentration $\left(\beta_{22}\right)$ & $-2.39^{\mathrm{a}}$ & $-1.47^{\mathrm{b}}$ & $-2.37^{\mathrm{a}}$ & $-3.43^{c}$ & $-6.57^{\mathrm{a}}$ \\
\hline Temperature $\times$ temperature $\left(\beta_{33}\right)$ & $-2.51^{\mathrm{a}}$ & $-0.64^{\mathrm{a}}$ & $-0.58^{\mathrm{a}}$ & $-1.43^{\mathrm{b}}$ & $-1.90^{\mathrm{a}}$ \\
\hline time $\times$ EtOH concentration $\left(\beta_{12}\right)$ & $-1.91^{\mathrm{a}}$ & $-1.21^{\mathrm{a}}$ & $-6.42^{\mathrm{d}}$ & $0.79^{\mathrm{a}}$ & $-0.40^{\mathrm{a}}$ \\
\hline time $\times$ temperature $\left(\beta_{13}\right)$ & $-1.61^{\mathrm{a}}$ & $-0.67^{\mathrm{a}}$ & $-4.20^{\mathrm{d}}$ & $0.42^{\mathrm{a}}$ & $-0.44^{\mathrm{a}}$ \\
\hline EtOH concentration $\times$ temperature $\left(\beta_{23}\right)$ & $0.04^{\mathrm{a}}$ & $0.23^{\mathrm{a}}$ & $6.75^{\mathrm{d}}$ & $0.28^{\mathrm{a}}$ & $-14.63^{\mathrm{b}}$ \\
\hline $\mathrm{R}^{2}$ & 0.68 & 0.73 & 0.75 & 0.98 & 0.81 \\
\hline F-value & 31.65 & 39.82 & 45.68 & 32.02 & 690.57 \\
\hline F-tabulated & 4.49 & 4.49 & 4.49 & 4.49 & 4.49 \\
\hline F ratio ${ }^{e}$ & 7.05 & 8.87 & 10.17 & 14.27 & 153.80 \\
\hline
\end{tabular}

95\% confidence level; ${ }^{\mathrm{a}}$ not significant $p>0.05$; ${ }^{\mathrm{b}}$ significant at $p<0.01$; ${ }^{\mathrm{c}}$ significant at $<0.001$; ${ }_{\mathrm{d}}^{\mathrm{d}}$ significant at $p<0.05$; ${ }^{\mathrm{e}} \mathrm{F}$ ratio (F-value/tabulated $\mathrm{F}$-value); GA: gallic acid; CUA: $p$-coumaric acid; DPPH: antioxidant activity; CA: caffeic acid; DW: dry weight. 
in temperature from 45 to $75{ }^{\circ} \mathrm{C}$ caused a $47 \%$ increase in content of $p$-coumaric acid when extracting with $80 \%$ EtOH (Table 2 and Figure 2).

Ethanol is less polar (1.69 dipole moment) than water (1.85 dipole moment) so by increasing the concentration of ethanol the polarity of the solvent extractor is decreased. The extraction of gallic acid has a maximum at around 65\% of ethanol and $p$-coumaric acid at $80 \%$. The difference between extractions of these compounds can be explained by the fact that gallic acid is a more polar compound than p-coumaric acid.

The interactions between the extraction time and temperature also influenced the extraction of phenolic $p$-coumaric acid. At an ethanol concentration of $80 \%$ and $75^{\circ} \mathrm{C}$, the content at 21 and $39 \mathrm{~min}$ was 34.2 and $17.7 \mu \mathrm{g} \mathrm{g}^{-1}$, runs R13 and R16, respectively. In comparison, the $p$-coumaric acid of the extracts at 21 and 39 min using $45^{\circ} \mathrm{C}$ was approximately 18.1 and $10.2 \mu \mathrm{g} \mathrm{g}^{-1}$, runs R3 and R4, respectively. The samples extracted at 21 and 39 min using 45 and $75^{\circ} \mathrm{C}$ were significantly different. An increase in time from 21 to 39 min caused a $48.4 \%$ decrease in content of $p$-coumaric acid when extracting with $75^{\circ} \mathrm{C}$ and $\mathrm{EtOH}$ $80 \%$.The maximum predicted CUA $\left(47.13 \mu \mathrm{g} \mathrm{g}^{-1}\right)$ was obtained under the extraction conditions of $50 \%$ of ethanol,

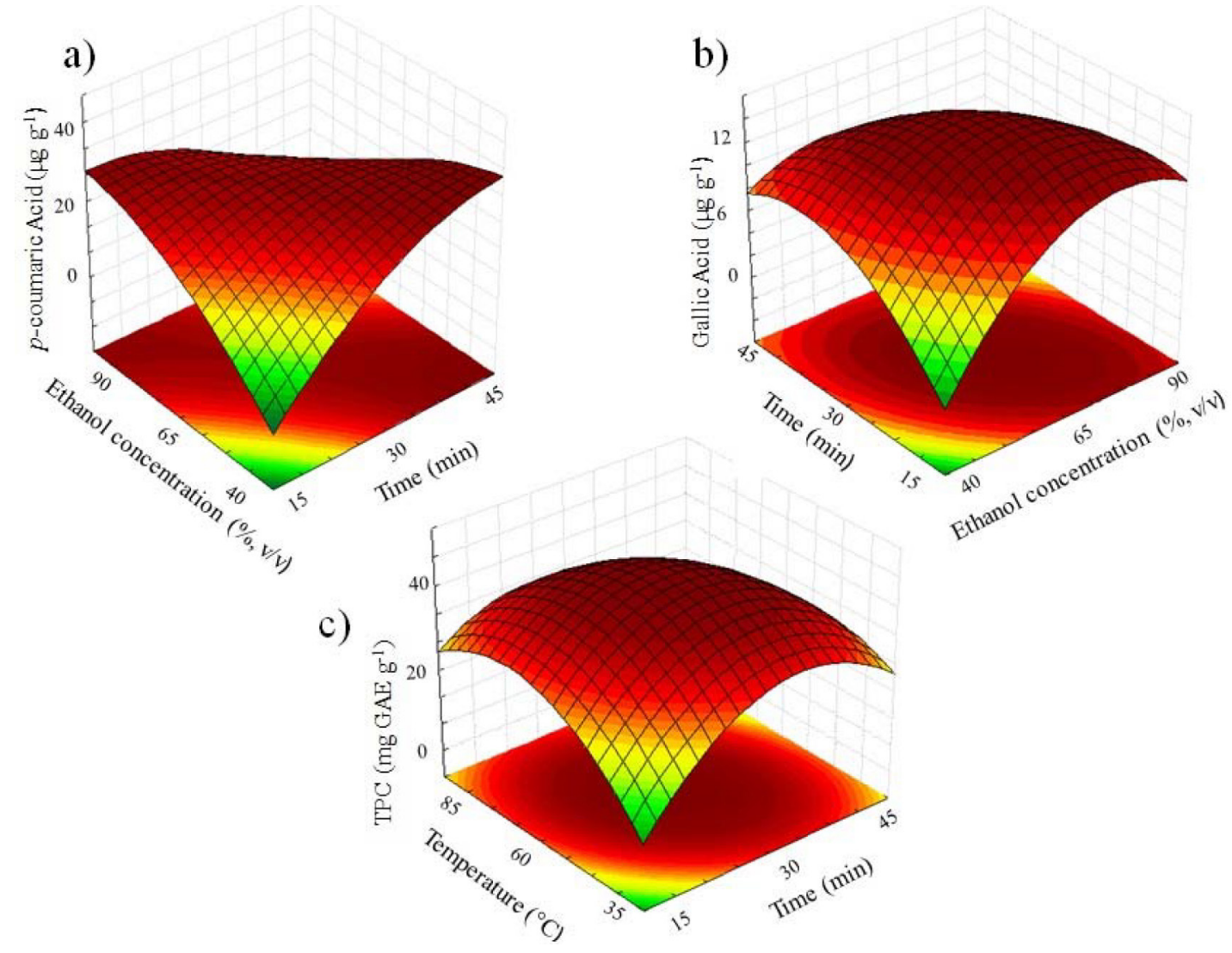

Figure 2. Responses surfaces obtained from EEGP: (a) $p$-coumaric acid as a function of ethanol concentration and time; (b) gallic acid as a function of

time and ethanol concentration; and (c) TPC as a function of temperature and time. $45^{\circ} \mathrm{C}$ and 39 min for EtOH concentration, temperature and time, respectively (Table 2).

Two-way joining analysis (Figure 3) confirms the maximum conditions for extraction of phenolic compounds and antioxidant activity from EEGP. This analysis evaluates the clustering of samples related to dependent variables. The intensity of color shows which dependent variable is more related to extracts produced in different conditions. For EEGP, runs R2, R3, R4 and R16 showed lowest results for all variables analyzed. Runs R9, R13, R11 and R10 showed the highest content of phenolic compounds and gallic acid, indicating a strong correlation between these results. The run R5 showed the highest content of $p$-coumaric acid and trans-resveratrol.

Because three variables ( $p$-coumaric acid, phenolic compounds and galic acid) were significant, presented distinct values and there is interest in obtaining the optimal operating condition of the independent variables, it was calculated the Desirability function. The calculated global value was 0.7784 for the conditions of $60{ }^{\circ} \mathrm{C}, 30 \mathrm{~min}$ and ethanol concentration of $65 \%$, which corresponds to the central point, simultaneously satisfying all the requirements necessary for dependent variables. Dependent variables that were influenced by the evaluated parameters (X1, X2 


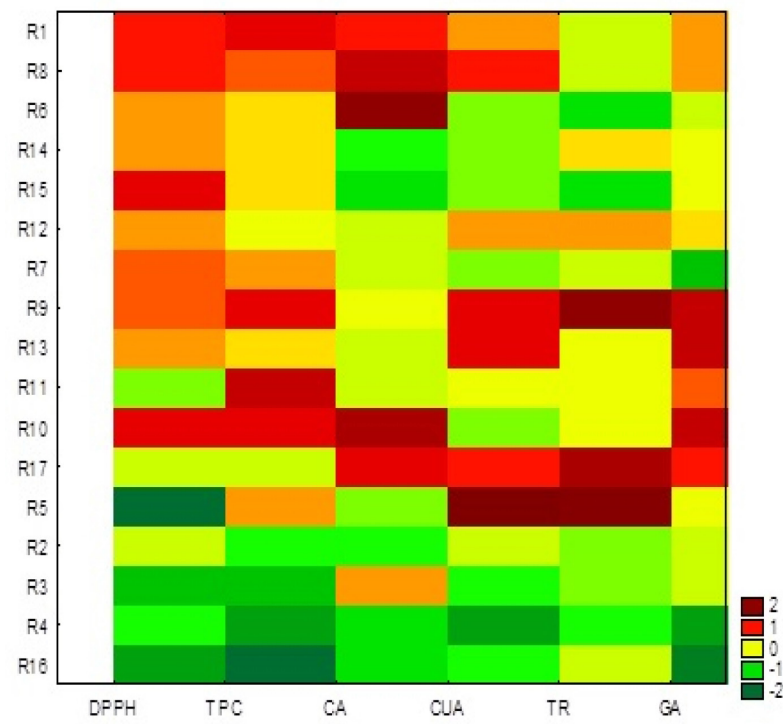

Figure 3. Two-way joining results for EEGP. Antioxidant activity (DPPH), total phenolic content (TPC), caffeic acid (CA), p-coumaric acid (CUA), trans-resveratrol (TR), gallic acid (GA).

and X3) were tested for lack of fit and showed adequacy $(p>0.05)$ of models.

Karacabey and Mazza ${ }^{3}$ using RSM in grape pomace also observed the effect of ethanol concentration and temperature on the extraction of compounds with antioxidant activity and the ethanol concentration was the most significant variable for the extraction of bioactive compounds. Other authors have also reported that the polarity of the solvent used in the extraction directly affects not only the amount of phenolic compounds but also the composition of phenolic compounds. ${ }^{34}$

\section{Optimum extraction conditions for apple pomace}

The variations observed for antioxidant activity and TPC obtained for the EEAP were 2.34 to $4.06 \mu \mathrm{mol}$ Trolox $\mathrm{g}^{-1}$ and 5.04 to $8.01 \mathrm{mg} \mathrm{GAE} \mathrm{g}^{-1}$ of dry apple pomace, respectively.

In extraction of phenolic compounds no independent variables were significant; however, the antioxidant activity by DPPH method was influenced by all tested variables (Table 3) with quadratic and linear effects. It was observed that when time and extraction temperature variables varied from lower level to higher level occurred an increase of $42.4 \%$ in antioxidant activity (Table 4).

The main effect, ethanol concentration was significant $(p<0.05)$ to extract compounds with antioxidant activity by DPPH method. The activity increased more than $40.0 \%$ when going from $80\left(2.34 \mu \mathrm{mol} \mathrm{g} \mathrm{g}^{-1}\right)$ to $50 \%$ $\left(4.06 \mu \mathrm{mol} \mathrm{g}^{-1}\right)$ EtOH concentration (Table 4). The effect of ethanol concentration can be related to decrease in polarity of solvent extraction due to the increase of ethanol concentration. Therefore a change in polarity of solvent coupled with temperature and time increase provided

Table 4. Central composite rotatory design and corresponding response values for ethanolic extract from apple pomace (EEAP)

\begin{tabular}{|c|c|c|c|c|c|c|}
\hline Run No. & $\mathrm{X} 1^{\mathrm{a}}$ & $\mathrm{X} 2^{\mathrm{b}}$ & $\mathrm{X} 3^{\mathrm{c}}$ & $\begin{array}{l}\text { Response DPPH }{ }^{\mathrm{d}} / \\
\left(\mu \mathrm{mol} \text { Trolox } \mathrm{g}^{-1} \mathrm{DW}\right)\end{array}$ & $\begin{array}{c}\text { Response TPC } / \\
\left(\mathrm{mg} \mathrm{GAE} \mathrm{g}^{-1} \mathrm{DW}\right)\end{array}$ & $\begin{array}{c}\text { Response } \mathrm{CA}^{\mathrm{f}} / \\
\left(\mu \mathrm{g} \mathrm{g}^{-1} \mathrm{DW}\right)\end{array}$ \\
\hline 1 & $45(-1)$ & $21(-1)$ & $50(-1)$ & 29.51 & 7.39 & 60.33 \\
\hline 2 & $45(-1)$ & 39 (1) & $50(-1)$ & 29.00 & 6.69 & 60.33 \\
\hline 3 & $45(-1)$ & $21(-1)$ & $80(1)$ & 17.60 & 6.65 & 58.50 \\
\hline 4 & $45(-1)$ & 39 (1) & $80(1)$ & 22.80 & 5.93 & 58.33 \\
\hline 5 & $75(1)$ & $21(-1)$ & $50(-1)$ & 32.86 & 6.42 & 61.83 \\
\hline 6 & $75(1)$ & $39(1)$ & $50(-1)$ & 36.59 & 6.49 & 58.50 \\
\hline 7 & $75(1)$ & $21(-1)$ & $80(1)$ & 24.63 & 7.27 & 57.50 \\
\hline 8 & $75(1)$ & 39 (1) & $80(1)$ & 28.93 & 6.82 & 59.67 \\
\hline 9 & $60(0)$ & $15(-1.68)$ & $65(0)$ & 29.04 & 7.69 & 33.17 \\
\hline 10 & $60(0)$ & $45(+1.68)$ & $65(0)$ & 32.35 & 7.86 & 60.00 \\
\hline 11 & $60(0)$ & $30(0)$ & $40(-1.68)$ & 29.24 & 8.01 & 60.33 \\
\hline 12 & $60(0)$ & $30(0)$ & $90(+1.68)$ & 19.09 & 5.04 & 60.00 \\
\hline 13 & $35(-1.68)$ & $30(0)$ & $65(0)$ & 24.01 & 7.50 & 59.17 \\
\hline 14 & $85(+1.68)$ & $30(0)$ & $65(0)$ & 35.58 & 7.30 & 57.16 \\
\hline 15 & $60(0)$ & $30(0)$ & $65(0)$ & 34.04 & 6.43 & 59.33 \\
\hline 16 & $60(0)$ & $30(0)$ & $65(0)$ & 34.17 & 6.55 & 60.33 \\
\hline 17 & $60(0)$ & $30(0)$ & $65(0)$ & 33.02 & 6.71 & 59.17 \\
\hline
\end{tabular}

${ }^{\mathrm{a} X} 1$ : temperature $\left({ }^{\circ} \mathrm{C}\right) ;{ }^{\mathrm{b}} \mathrm{X} 2$ : time (min); ${ }^{\mathrm{C} X} 3$ : ethanol concentration $(\%)$; ${ }^{\mathrm{d}} \mathrm{DPPH}$ : antioxidant activity; ${ }^{\mathrm{e}} \mathrm{TPC}$ : total phenolic content; ${ }^{\mathrm{f}} \mathrm{CA}$ : level of caffeic acid. 

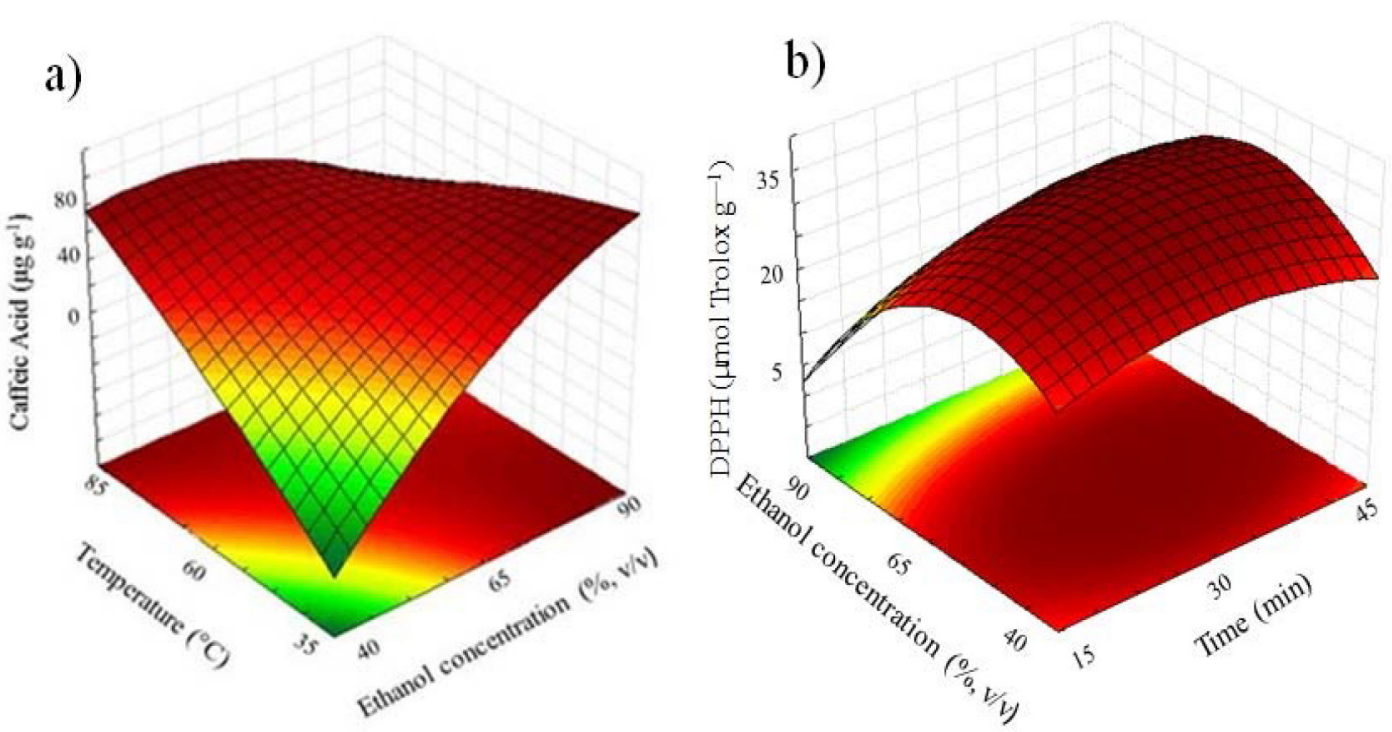

Figure 4. Responses surfaces obtained from EEAP (a) caffeic acid as a function of temperature and ethanol concentration and (b) DPPH as a function of ethanol concentration and time.

the maximum extraction of compounds with antioxidant activity from apple pomace which indicates the heat stability of these compounds.

In the extraction of caffeic acid only the time factor was not significant, while the independent variable temperature and ethanol concentration, as well as the interaction between ethanol concentration and temperature were significant (Table 3). It is possible to suggest that caffeic acid shows heat stability and a better affinity with medium less polar. The maximum predicted caffeic acid $\left(61.83 \mu \mathrm{g} \mathrm{g}^{-1}\right)$ evaluated by HPLC was obtained under extraction conditions of $50 \%$ of ethanol concentration and $75{ }^{\circ} \mathrm{C}$ (Table 4 and Figure 4).

Two-way joining analysis for EEAP (Figure 5) showed that runs R3, R4 and R12 presented the lowest content of phenolic compounds and antioxidant activity while R9 extracted lower content of $p$-coumaric acid.

Wijngaard and Brunton ${ }^{35}$ reported in apple pomace that only the temperature had a significant effect on the model response for antioxidant activity using DPPH method while concentration of ethanol plays the most important role to extract individual polyphenol groups as phenolic acids and flavonoids.

Using ANOVA, it was observed that models were significant and predictive. F calculated was 14.27 and 153.80 times higher than F tabulated for DPPH method and caffeic acid, respectively, with 95\% confidence (Table 3). The models had satisfactory levels of adequacy $\left(\mathrm{R}^{2}\right)$.

For apple pomace, DPPH and caffeic acid variables were significant and from the Desirability function (0.7025), optimal extraction conditions were $60^{\circ} \mathrm{C}, 30 \mathrm{~min}$ and ethanol concentration of $65 \%$, corresponding to the

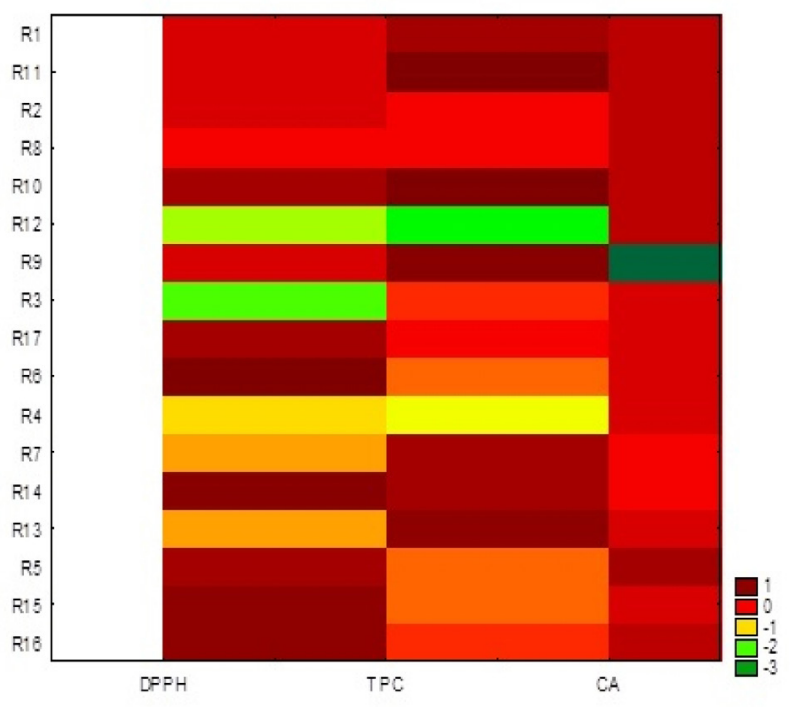

Figure 5. Two-way joining results for EEAP. Antioxidant activity (DPPH), total phenolic content (TPC), caffeic acid (CA).

central point, same condition obtained for grape pomace. The lack of fit calculated was not significant for DPPH model $(p>0.05)$ while for the caffeic acid model the value was less than 0.05 , indicating that the model is inadequate.

\section{Conclusions}

Effects of time, temperature and ethanol concentration on antioxidant activity and phenolic compounds of grape and apple pomaces were determined by response surface methodology (RSM). The optimization procedure was conducted in order to simultaneously maximize the antioxidant activity by DPPH method, total phenolic 
content and individual phenolic acids and stilbene transresveratrol.

From desirability function it was possible to establish that optimal conditions of extractions for both pomaces were the independent variables in central point. On the whole, it is interesting to note that grape and apple pomaces from Southern of Brazil are a valuable source of natural antioxidants and have properties that suggest applications in the food and pharmaceutical industries.

\section{Acknowledgments}

The authors acknowledge grants and fellowships from Conselho Nacional de Desenvolvimento Científico e Tecnológico (CNPq-Process No. 476635/2013-6), Central de Análises and Diretoria de Pesquisa ePós-Graduação (DIRPPG) of Federal Technological University of Paraná (UTFPR).

\section{References}

1. Melo, P. S.; Bergamaschi, K. B.; Tiveron, A. P.; Massarioli, A. P.; Oldoni, T. L. C.; Zanus, M. C.; Pereira, G. E.; de Alencar, S. M.; Cienc. Rural 2011, 41, 1088.

2. Sautter, C. K.; Denardin, S.; Alves, A. O.; Mallmann, C. A.; Penna, N. G.; Hecktheuer, L. H.; Food Sci. Technol. 2005, 25, 437.

3. Karacabey, E.; Mazza, G.; Food Chem. 2010, 119, 343.

4. Sang, S.; Yang, I.; Buckley, B.; Ho, C. T.; Yang, C. S.; Free Radical Biol. Med. 2009, 43, 362.

5. Leyva-Corral, J.; Quintero-Ramos, A.; Camacho-Dávila, A.; Zazueta-Morales, J. J.; Aguilar-Palazuelos, E.; Ruiz-Gutiérrez, M. G.; Meléndez-Pizarro, C. O.; Ruiz-Anchondo, T. D. J.; Food Sci. Technol. 2016, 65, 228.

6. Rana, S.; Gupta, S.; Rana, A.; Bhushan, S.; Food Science Human Wellness 2015, 4, 180.

7. Soares, M.; Welter, L.; Gonzaga, L.; Lima, A.; Mancini-Filho, J.; Fett, R.; Food Sci. Technol. 2008, 28, 727.

8. Tournour, H. H.; Segundo, M. A.; Magalhães, L. M.; Barreiros, L.; Queiroz, J.; Cunha, L. M.; Ind. Crops Prod. 2015, 74, 397.

9. Llobera, A.; Cañellas, J.; Food Chem. 2007, 101, 659.

10. Lommen, A.; Godejohann, M.; Venema, D. P.; Hollman, P. C. H.; Spraul, M.; Anal. Chem. 2000, 72, 4431.

11. Prozil, S. O.; Mendes, J. A.; Evtuguin, D. V.; Lopes, L. P. C.; Millenium 2013, 44, 23.

12. Guyot, S.; Marnet, N.; Sanoner, P.; Drilleau, J. F.; J. Agric. Food Chem. 2003, 6240.

13. Domínguez-Perles, R.; Teixeira, A. I.; Rosa, E.; Barros, A. I.; Food Chem. 2014, 164, 339.

14. Macagnan, F. T.; dos Santos, L. R.; Roberto, B. S.; Moura, F. A.; Bizzani, M.; Silva, L. P.; Bioact. Carbohydr. Diet. Fibre 2015, 6,1 .
15. Oldoni, T. L. C.; Melo, P. S.; Massarioli, A. P.; Moreno, I. A. M.; Bezerra, R. M. N.; Rosalen, P. L.; da Silva, G. V. J.; Nascimento, A. M.; Alencar, S. M.; Food Chem. 2016, 192, 306.

16. Bucic-Kojic, A.; Sovová, H.; Planinic, M.; Tomas, S.; Food Chem. 2013, 136, 1136.

17. Mielnik, M. B.; Olsen, E.; Vogt, G.; Adeline, D.; Skrede, G.; Food Sci. Technol. 2006, 39, 191.

18. Peschel, W.; Sánchez-Rabaneda, F.; Diekmann, W.; Plescher, A.; Gartzía, I.; Jiménez, D.; Lamuela-Raventós, R.; Buxaderas, S.; Codina, C.; Food Chem. 2006, 97, 137.

19. Tseng, A.; Zhao, Y.; Food Chem. 2013, 138, 356.

20. Shirahigue, L. D.; Plata-Oviedo, M.; Alencar, S. M.; D’Arce, M. A. B. R.; Vieira, T. M. F. S.; Oldoni, T. L. C.; Int. J. Food Sci. Technol. 2010, 45, 863.

21. Drosou, C.; Kyriakopoulou, K.; Bimpilas, A.; Tsimogannis, D.; Krokida, M.; Ind. Crops Prod. 2015, 75, 141.

22. Farhadi, K.; Esmaeilzadeh, F.; Hatami, M.; Forough, M.; Molaie, R.; Food Chem. 2016, 199, 847.

23. Jara-Palacios, M. J.; Hernanz, D.; Cifuentes-Gomez, T.; Escudero-Gilete, M. L.; Heredia, F. J.; Spencer, J. P. E.; Food Chem. 2015, 183, 78.

24. Zhu, F.; Du, B.; Zheng, L.; Li, J.; Food Chem. 2015, 186, 207.

25. Rockenbach, I. I.; Gonzaga, L. V.; Rizelio, V. M.; Gonçalves, A. E. S. S.; Genovese, M. I.; Fett, R.; Food Res. Int. 2011, 44, 897.

26. Ghafoor, K.; Park, J.; Choi, Y. H.; Innovative Food Sci. Emerging Technol. 2010, 11, 485.

27. Montgomery, D. C.; Design and Analysis of Experiments, $8^{\text {th }}$ ed.; John Wiley: New York, 2012.

28. Oldoni, T. L. C.; Oliveira, S. C.; Andolfatto, S.; Karling, M.; Calegari, M. A.; Sado, R. Y.; Maia, F. M. C.; Alencar, S. M.; Lima, V. A.; J. Braz. Chem. Soc. 2015, 26, 2054.

29. Zordi, N.; Cortesi, A.; Kikic, I.; Moneghini, M.; Solinas, D.; Innocenti, G.; Portolan, A.; Baratto, G.; Dall'Acqua, S.; J. Supercrit. Fluids 2014, 95, 491.

30. Singleton, V. L.; Orthofer, R.; Lamuela-Raventós, R. M.; Methods Enzymol. 1999, 299, 152.

31. Brand-Williams, W.; Cuvelier, M.; Berset, C.; Lebensm-Wiss. Techonol. 1995, 28, 25.

32. Alberti, A.; Zielinski, A. A. F.; Zardo, D. M.; Demiate, I. M.; Nogueira, A.; Mafra, L. I.; Food Chem. 2014, 149, 151.

33. García, Y. D.; Valles, B. S.; Lobo, A. P.; Food Chem. 2009, 117, 731.

34. Yu, J.; Ahmedna, M.; Goktepe, I.; Food Chem. 2005, 90, 199.

35. Wijngaard, H. H.; Brunton, N.; J. Food Eng. 2010, 96, 134.

Submitted: August 29, 2016 Published online: February 3, 2017 